\title{
Machine Learning of Surface Layer Property Prediction for Milling Operations
}

\author{
Eckart Uhlmann ${ }^{1,2}$, Tobias Holznagel ${ }^{2, *}$, Philipp Schehl ${ }^{2}$ and Yannick Bode ${ }^{2}$ \\ 1 Fraunhofer Institute for Production Systems and Design Technology IPK, Pascalstraße 8-9, 10587 Berlin, \\ Germany; eckart.uhlmann@ipk.fraunhofer.de \\ 2 Institute for Machine Tools and Factory Management, Technische Universität Berlin, Pascalstraße 8-9, \\ 10587 Berlin, Germany; p.schehl@campus.tu-berlin.de (P.S.); y.bode@campus.tu-berlin.de (Y.B.) \\ * Correspondence: tobias.holznagel@iwf.tu-berlin.de; Tel.: +49-30-314-23998
}

Citation: Uhlmann, E.; Holznagel, T. Schehl, P.; Bode, Y. Machine Learning of Surface Layer Property Prediction for Milling Operations. J. Manuf. Mater. Process. 2021, 5, 104. https:// doi.org/10.3390/jmmp5040104

Academic Editors: Arkadiusz Gola Izabela Nielsen and Patrik Grznár

Received: 27 August 2021

Accepted: 27 September 2021

Published: 30 September 2021

Publisher's Note: MDPI stays neutral with regard to jurisdictional claims in published maps and institutional affiliations.

Copyright: (c) 2021 by the authors. Licensee MDPI, Basel, Switzerland. This article is an open access article distributed under the terms and conditions of the Creative Commons Attribution (CC BY) license (https:/ / creativecommons.org/licenses/by/ $4.0 /)$.

\begin{abstract}
Tool wear and cutting parameters have a significant effect on the surface layer properties in milling. Since the relation between tool wear, cutting parameters, and surface layer properties is mostly unknown, the latter cannot be controlled during production and may vary from part to part as tool wear progresses. To account for this uncertainty and to prevent premature failure, components often need to be oversized or surface layer properties need to be adjusted in subsequent manufacturing processes. Several approaches have been made to obtain models that predict the surface layer properties induced by manufacturing processes. However, those approaches need to be calibrated with a considerable number of experimental trials. As trials are time-consuming and surface layer measurements are laborious, no industrial applications have been realized. Complex models have one major drawback. They have to be re-parameterized as soon as process characteristics change. Therefore, manual experimental parameterization does not appear to be a feasible approach for industrial application. A highly automated approach for the machine learning of the relation between tool wear, cutting parameters and surface layer properties is presented in this paper. The amount of obtained measurement data allows a fundamental analysis of the approach, which paves the way for further developments.
\end{abstract}

Keywords: surface engineering; milling; machine learning; evolution strategy; surface layer properties

\section{Introduction}

Surface layer properties (SLP) of a workpiece, such as microhardness, martensite content, and compressive or tensile residual stresses, are influenced by temperatures and temperature gradients, which occur in the cutting zone during milling [1]. Mechanical tension and high strain rates might lead to severe plastic deformation and thus to the formation of nanocrystalline structures, resulting in an increase in tensile strength [2]. Accordingly, SLP have a significant impact on component life and premature failure, e.g., compressive residual stresses in the surface layer that prevent crack propagation [3-5]. Since plastic deformation and cutting temperatures are the result of forming, shear, friction, material separation, and material redirection, which are subjected to disturbances such as increasing tool wear and rising tool temperature, the manufactured SLP vary considerably over tool life.

The SLP are in most cases not monitored by quality control in the manufacturing industry or used as a feedback value for further production. To prevent premature failure of a critical part caused by lack of process knowledge in manufacturing, it is often necessary to design parts with safety factors [6]. This results in heavy and oversized components. Downstream processes such as heat treatments [7], plasma nitriding [8], deep rolling [9], or shot peening $[10,11]$ offer an industrially applicable possibility for the defined configuration of SLP. Major disadvantages of these approaches are the significant time and cost 
expenditures, which are caused by additional processes and necessary component inspection. Therefore, it would be desirable to at least keep SLP within defined limits during the milling process with cutting parameter adaption, which compensates the influence of increasing tool wear on SLP.

Since modern surface layer measurement hardware, e.g., Barkhausen noise or eddy current sensors, are susceptible to vibrations, electromagnetic fields, temperature deviations in the workpiece, and cooling lubricant, direct measurement of SLP parallel to the milling process remains challenging [12-15]. Several approaches have been made to overcome this challenge by teaching soft sensors or creating analytical or FE-models [5]. Due to the complexity of the milling process as well as the high experimental effort required to calibrate the models for the specific milling setup, no industrial application with direct SLP measurement parallel to the milling process has been realized to this date.

However, the interactions between manipulated variables of the cutting process, tool wear state, thermal and mechanical load in the surface layer and the manufactured SLP are subject of several preliminary works. Investigations on cutting parameters and disturbances on target variables such as hardness, residual stresses, and workpiece microstructure are presented in the following section.

Influence of cutting parameters on SLP are mentioned in standard reference works for different machining processes $[1,16,17]$. Several researchers report relations between cutting speed $v_{c}$, tool feed $f_{z}$, cutting width $a_{e}$ and the resulting SLP [3,18-22]. Microhardness and residual stresses are influenced differently depending on the feed direction [23,24]. The influence of the cooling strategy for milling [25] and hard machining [26,27] was shown as well. Other preliminary works report the impact of ultrasonic assistance on SLP in milling [28,29]. Furthermore, it was shown that tool wear state has a significant effect on SLP [3,30-33]. Other works showed the consequences of tool substrate [3,31], tool coating [34], cutting edge chamfer [3,35,36] and rake angle variation [37]. Different workpiece materials and initial material properties influence manufactured SLP as well [38-40]. Zahoor et al. [41,42] report on the influence of tool vibrations, which are heavily dependent on the specific spindle and tool holder, on resulting SLP. Ulutan and Özel [43] published a comprehensive review on machining-induced SLP changes. A more recent review was given by Sales et al. [5] in 2020 .

SLP prediction and control during machining was subject to various research activities over the past 20 years. The proposed systems can be subdivided into numerical, analytical, empirical, and soft-sensing approaches. The different academic developments will be presented in the following section.

El-Axir [44] calculates residual stress profiles based on the assumption that they are only dependent on initial tensile strength and the cutting parameters. Wang et al. [45] developed an FE-based model for the simulation of residual stress profiles in high-speed machining, without experimental validation. Zhang et al. [46] trained a neural network (NN) using experimental data. The NN uses cutting parameters, coolant type, tool wear, workpiece material, and tool geometries as the input and outputs the longitudinal and circumferential residual stress profiles. The presented results show good agreement between predictions and experimental data. Umbrello et al. $[47,48]$ taught an NN to predict subsurface residual stresses when inputting cutting parameters and initial workpiece hardness for hard turning. They consider purely empirical models to be inapplicable due to their excessive experimental expenditure, an FE-model to be neither suitable nor sufficiently robust, and therefore use a hybrid FE-NN approach. Saini et al. [49] developed linear regression models on residual stress for turning while neglecting tool wear. They observed depth of cut $\mathrm{a}_{\mathrm{p}}$ and tool feed $\mathrm{f}_{\mathrm{z}}$ as being relevant. However, the influence of the tool nose radius $r_{\beta}$ and cutting speed $v_{c}$ is seen as less relevant for modeling. Ulutan et al. [50] also judge analytical and FE-based approaches for the prediction of SLP as making too many assumptions and idealizations. Therefore, they proposed the fitting of sinusoidal decay functions on the residual stress profile. Wang et al. [51] also consider FE-simulations to be inaccurate and time consuming and fitted a decaying cosine function for the residual stress 
profile and calculated its parameters with a regression on cutting parameters. Schulze et al. [52] evaluated different approaches for modeling the phase transformations in machining. Huang et al. [53] developed an efficient analytical model for the prediction of the residual stress profile. However, validation with experimental data remains vague. Yang et al. [54] proposed an analytical model for residual stress calculation for the orthogonal cutting process which also took heat generation into account. Uhlmann et al. [55] proposed a FEM approach for hard turning with consideration of phase transformations. Stampfer et al. [56] considered cutting force measurement insufficient for the development of a soft sensor and propose further process measurands such as acoustic emission. Meurer et al. [57] proposed a surface integrity sensor based on cutting force to predict white layer thickness. The predicted white layer thickness values showed deviations of more than 100\% to experimental data. Uebel et al. [40] proposed a soft sensor based on force, temperature, pneumatic, and angle resolved scattered light sensor measurement. Fricke et al. [58-60] developed an eddy current sensor measurement in combination with a cutting simulation for the online prediction of martensite content during turning.

For the realization in industrial applications, manufacturers must be enabled to parameterize SLP models for the specific process characteristics, workpiece, and machine setup on hand to make reliable predictions and adapt cutting parameter accordingly. One feasible approach is the automation of the experimental step to gain sufficient process data quickly and reliably. A demonstrator of such a setup has been realized by the authors and is discussed in this paper.

\section{Materials and Methods}

For the development of the presented approach, the UltraSonic C260 Composites machine tool by Sauer GMBH, Stipshausen, Germany, with a Sinumerik 840d SL CNCcontrol and an OPC UA SW 3.0 SP1-server of the company Siemens AG, Munich, Germany, was used. The installed milling spindle was of type MFW-1412/40 HSK-E50 CSC by Fischer AG Präzisionsspindeln, Herzogenbuchsee, Switzerland. The uncoated solid carbide end mill F4114 with a diameter of $d=16 \mathrm{~mm}$, a helix angle of $\mathrm{h}_{\mathrm{a}}=30^{\circ}$, a rake angle of $\gamma=8^{\circ}$, a clearance angle of $\alpha=9^{\circ}$, and four cutting edges by Schwegler Werkzeugfabrik GMBH \& Co. KG, Vöhringen, Germany, was clamped in a tool holder powRgrip HSK F63/PG25x100H by REGO-Fix AG, Tenniken, Switzerland. The milling tool consists of K10 microsubstrate. As a workpiece, a rolled and sawed plate 42CrMo4 + QT (1.7225) with a tensile strength of $R_{m}=1042 \mathrm{~N} / \mathrm{mm}^{2}$ by AG Der Dillinger Hüttenwerke, Dillingen, Germany, was used. The initial state of the workpiece was measured to maximum Barkhausen noise amplitude $\mathrm{M}_{\text {Max,init }}=0.28 \mathrm{~V}$ and coercive force $\mathrm{H}_{\mathrm{cm} \text {,init }}=22 \mathrm{~A} / \mathrm{m}$. To avoid damage to the surface layer measurement hardware, only dry cutting experiments with air cooling were conducted. To keep the cutting width constant, cutter radius compensation G41 was turned on. Each cut was conducted as a straight line with the cutting width of $\mathrm{a}_{\mathrm{e}}=0.5 \mathrm{~mm}$ and an axial depth $\mathrm{a}_{\mathrm{p}}=30 \mathrm{~mm}$ at a cutting length of $\mathrm{c}_{1}=100 \mathrm{~mm}$.

To obtain micromagnetic measurands, which can be employed to indirectly quantify the mechanical SLP, a 3MA-II-sensor by Fraunhofer IZFP, Saarbrücken, Germany, was used. The tool wear was quantified by measuring the tool radius reduction $\Delta \mathrm{r}$ using the laser measurement system LaserControl NT by Blum-Novotest GMBH, Grünkraut, Germany. The micromagnetic measurands and tool radius reduction $\Delta \mathrm{r}$ were measured after each cut. To gain statistical security, for each run nine surface layer measurements were performed, with the sensor being moved away and back again three times in between. For each milling process, power consumptions, electric currents and voltages of the Sinamics motor modules were recorded with a sampling rate of $\mathrm{f}_{\mathrm{S}}=1 \mathrm{kHz}$ using core current transformers KUW1/30-100 by Janitza Electronic GMBH, Lahnau, Germany.

After initialization, all cutting processes, micromagnetic measurements (MM) and tool wear measurements are conducted autonomously and one after the other. All actions of the machine tool and measurement equipment were controlled by a Python 3.9.5 script by Python Software Foundation, DE, USA. To trigger the 3MA-II-sensor to start measuring and 
to receive and send machine tool data, the Python script communicated with TwinCAT3 software by Beckhoff GMBH \& Co. KG, Verl, Germany, running on the same computer via ADS. Measurement data of the 3MA-II-sensor were written to a txt-file and then fetched and parsed by the Python script. The communication between machine tool, laser measurement system, and PC was realized by an OPC-client in TwinCAT and the OPC-server running on the CNC-control. One experiment lasted around two minutes, depending on the cutting parameters. The setup and dataflow are visualized in Figure 1.

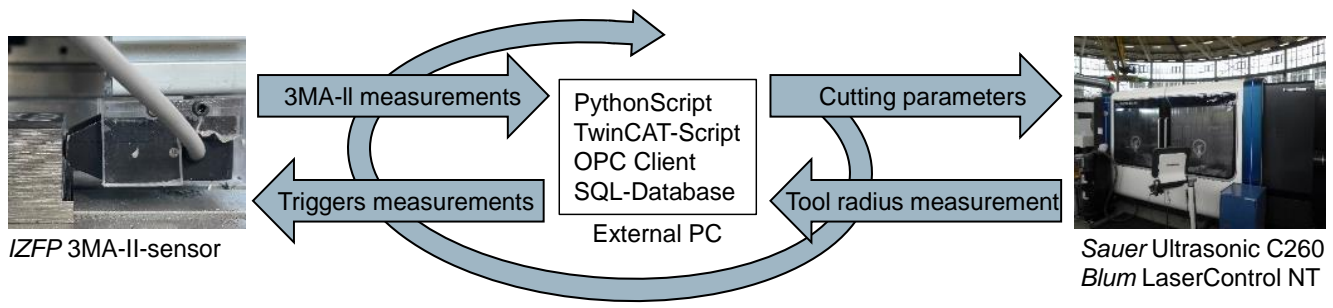

Figure 1. Dataflow of the developed data-driven surface layer property prediction setup.

To identify cutting parameters, which result in desired MM, the system performed a non-elitist evolution strategy with nine offspring. Initial cutting parameters are set according to tool manufacturers' recommendations. Offspring $i$ is then defined by its cutting velocity $\mathrm{v}_{\mathrm{c}, \text { Offspring,i }}$ and feed per tooth $\mathrm{f}_{\mathrm{z}, \text { Offspring, } \mathrm{i}}$ using Equations (1) and (2):

$$
\begin{gathered}
\mathrm{v}_{\mathrm{c}, \text { Offspring,i }}=\mathrm{v}_{\mathrm{c}, \text { Parent }}+\operatorname{sign}_{\mathrm{vc}, \mathrm{i}} \times \mathrm{m}_{\mathrm{vc}, \mathrm{i}} \\
\mathrm{f}_{\mathrm{z}, \text { Offspring,i }}=\mathrm{f}_{\mathrm{z}, \text { Parent }}+\operatorname{sign}_{\mathrm{fz}, \mathrm{i}} \times \mathrm{m}_{\mathrm{fz}, \mathrm{i}}
\end{gathered}
$$

where $\operatorname{sign}_{\mathrm{i}}$ is randomly set to either ' + ' or ' - ' and $\mathrm{m}$ is a normally distributed random value with a mean of $\mu=0$ and standard deviations $\sigma_{\mathrm{vc}}=20$ and $\sigma_{\mathrm{fz}}=0.02$, respectively. Standard deviations are adapted according to the $1 / 5$ success rule which states that the number of successful mutations to all mutations is best set to $\mathrm{sr}_{\mathrm{g}}=1 / 5$. If $\mathrm{sr}_{\mathrm{g}}$ is higher, step size of the next generation $g+1$ is increased and decreased when smaller than $1 / 5$. Following, Equation (3) is used:

$$
\sigma_{\mathrm{g}+1}=\left\{\begin{aligned}
0.85 \times \sigma_{\mathrm{g}} & \leftrightarrow \mathrm{sr}_{\mathrm{g}}<1 / 5 \\
\sigma_{\mathrm{g}} & \leftrightarrow \mathrm{sr}_{\mathrm{g}}=1 / 5 \\
\sigma_{\mathrm{g}} & \leftrightarrow \mathrm{sr}_{\mathrm{g}}>1 / 5
\end{aligned}\right.
$$

As soon as one offspring achieves acceptable MM, the evolution strategy is aborted and a design of experiments is conducted where this offspring serves as center point. The acceptable MM were defined as the maximum amplitude of Barkhausen noise of $\mathrm{M}_{\mathrm{Max}}<0.25 \mathrm{~V}$ and a coercive force of $\mathrm{H}_{\mathrm{cm}}<28 \mathrm{~A} / \mathrm{m}$ at a frequency of $\mathrm{f}=600 \mathrm{~Hz}$ and a magnetization amplitude of $\mathrm{H}_{\mathrm{Max}}=40 \mathrm{~A} / \mathrm{cm}$. This sensor configuration results in a measuring depth of around $\mathrm{D}=35 \mu \mathrm{m}$. The other cutting parameters of the experimental design are identified with the lower limits $\mathrm{f}_{\mathrm{Z}, \mathrm{LL}}=0.01 \mathrm{~mm}$ and $\mathrm{v}_{\mathrm{C}, \mathrm{LL}}=40 \mathrm{~m} / \mathrm{min}$ as well as the upper limits $\mathrm{f}_{\mathrm{z}, \mathrm{UL}}=0.2 \mathrm{~mm}$ and $\mathrm{v}_{\mathrm{C}, \mathrm{UL}}=120 \mathrm{~m} / \mathrm{min}$ using following set of Equation (4):

$$
\begin{gathered}
\mathrm{v}_{\mathrm{c} \text {,high }}=\mathrm{v}_{\mathrm{c} \text {,center }}+\left(\mathrm{v}_{\mathrm{c}, \mathrm{UL}}-\mathrm{v}_{\mathrm{c}, \mathrm{LL}}\right) \times 0.05 \\
\mathrm{v}_{\mathrm{c} \text {,low }}=\mathrm{v}_{\mathrm{c} \text {,center }}-\left(\mathrm{v}_{\mathrm{c}, \mathrm{UL}}-\mathrm{v}_{\mathrm{c}, \mathrm{LL}}\right) \times 0.05 \\
\mathrm{f}_{\mathrm{z} \text {,high }}=\mathrm{f}_{\mathrm{z} \text {,center }}+\left(\mathrm{f}_{\mathrm{z}, \mathrm{UL}}-\mathrm{f}_{\mathrm{z}, \mathrm{LL}}\right) \times 0.05 \\
\mathrm{f}_{\mathrm{z} \text { low }}=\mathrm{f}_{\mathrm{z} \text {,center }}-\left(\mathrm{f}_{\mathrm{z}, \mathrm{UL}}-\mathrm{f}_{\mathrm{z}, \mathrm{LL}}\right) \times 0.05
\end{gathered}
$$

Experiments were performed until a tool radius reduction of $\Delta \mathrm{r}=175 \mu \mathrm{m}$ was exceeded, which corresponded with a wear mark width of $\mathrm{VB}=600 \mu \mathrm{m}$. Measurement data of the cable core converters, all 3MA-II-sensor outputs, and the tool radius measurement were logged to a SQL-database. These data were then analyzed and further processed to gain knowledge on MM and tool wear behavior of the milling process configuration 
under investigation. Machine learning and model investigation was executed with GMDH Shell 3.8.9, GMDH Inc., New York, NY, USA, as well as RapidMiner Studio Free 9.9.002, Rapidminer GMBH, Dortmund, Germany, and the Python library scikit-learn 0.24.2.

\section{Results}

During the experiments with the presented setup, four milling tools reached the wear criterium. An overall of 826 experiments were conducted, which could be subdivided into 522 data points for evolution strategy and 304 for the design of the experiment. Analysis and processing of the measurement data obtained is presented in the following sections.

\subsection{MA-II-Sensor Measurements}

The 3MA-II-sensor shows constant reproducibility for all measurement values. No heteroskedasticity was observed as the standard deviation showed a constant average of $0.007 \mathrm{~V}$ for all measured averaged values of maximum Barkhausen noise amplitude $\mathrm{M}_{\mathrm{Max}}$ in the range of $0.169 \mathrm{~V}$ to $0.332 \mathrm{~V}$. The coercive force shows a constant reproducibility with a standard deviation of $0.32 \mathrm{~A} / \mathrm{m}$. As 3MA-II measurements were executed $3 \times 3$ times after each cut, a shift in maximum Barkhausen noise amplitude values could be observed ranging from $0 \mathrm{~V}$ to $0.0014 \mathrm{~V}$ on average between first and ninth measurement which is attributed to the workpiece cooling down and the sensor heating up. For three measurements, during which the sensor is not removed from the milled surface, absolute reproducibility of the measurand ranges between $\pm 0.2 \mathrm{mV}$.

\subsection{Cable Core Converters Measurements}

Power consumption $\mathrm{P}_{\mathrm{M} \text {,Mean }}$ of the motor module was measured via the sum of the three phase currents of its power supply. Measurements showed high correlation with the tool radius reduction $\Delta \mathrm{r}$ of $\mathrm{r}_{\mathrm{PM}, \mathrm{Mean}, \Delta \mathrm{r}}=0.95$. As tool radius reduction progressed from $\Delta \mathrm{r}=20$ to $\Delta \mathrm{r}=180 \mu \mathrm{m}$, motor module power $\mathrm{P}_{\mathrm{M}, \text { Mean }}$ almost doubled from around $\mathrm{P}_{\mathrm{M} \text {,Mean }}=2000$ to more than $\mathrm{P}_{\mathrm{M} \text {,Mean }}=4000 \mathrm{~W}$. Deviations, which are also observable in Figure 2, mainly derived from varying the cutting parameters feed per tooth $\mathrm{f}_{\mathrm{z}}$ and cutting speed $\mathrm{v}_{\mathrm{c}}$. Since power consumption was not constant during one experiment, the power measurement time series data was averaged for each cutting experiment.

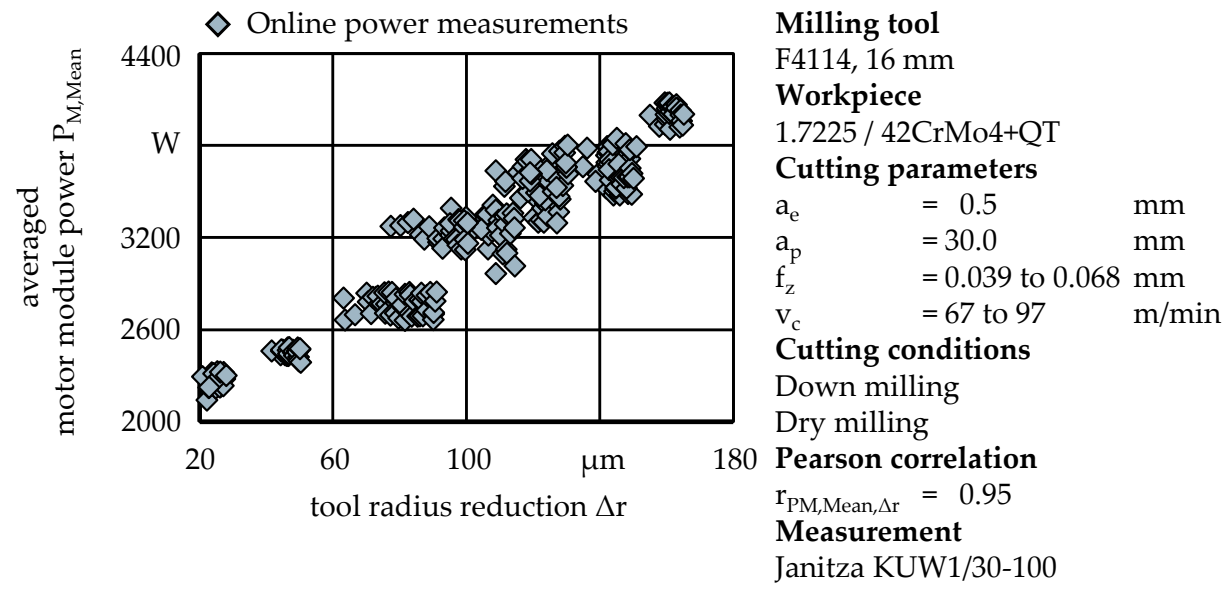

Figure 2. Averaged power measurements $\mathrm{P}_{\mathrm{M}, \mathrm{Mean}}$ correlation to tool radius reduction $\Delta \mathrm{r}$.

When teaching a combinatorial model in GMDH Shell, with $\Delta \mathrm{r}$ as target value and $\mathrm{f}_{\mathrm{z}}$ $\mathrm{P}_{\mathrm{M}, \text { Mean }}, \mathrm{v}_{\mathrm{C}}$ and their cube roots as input variables, a coefficient of determination $\mathrm{R}^{2}>0.96$ with mean absolute error $\mathrm{MAE}_{\Delta \mathrm{r}}<6 \mu \mathrm{m}$ was reached on the testing data set. Further inputs to improve model performance could not be identified. Even when $80 \%$ of the dataset were held out for the testing data set, and only the remaining $20 \%$ were used for the training data set, a coefficient of determination $\mathrm{R}^{2}>0.95$ was reached. For samples with a low radius reduction $\Delta \mathrm{r}<50 \mu \mathrm{m}$, model performance was declining. Since the tool 
wear rate was so high for the unused tool, only a few samples could be obtained in in the range $0<\Delta \mathrm{r}<50 \mu \mathrm{m}$. Therefore, the mean absolute error rises to $\mathrm{MAE}_{\Delta \mathrm{r}, \Delta \mathrm{r}}<50<73 \mu \mathrm{m}$. Still, online power measurement shows great potential for obtaining information about the state of flank wear conditions in the cutting zone and is further utilized in this paper for modeling and predicting the MM.

\subsection{Relationship of Cutting Parameters, Tool Radius Reduction, and Micromagnetic Measurements}

When cutting with constant cutting parameters, a significant influence of tool radius reduction $\Delta \mathrm{r}$ on maximum Barkhausen noise amplitude $\mathrm{M}_{\mathrm{Max}}$ and further measurands of the 3MA-II-sensor was observed. For this study, constant parameters were chosen according to the manufacturer's recommendations for the dry, down milling process to a feed per tooth $\mathrm{f}_{\mathrm{z}}=0.05 \mathrm{~mm}$, and cutting speed $\mathrm{v}_{\mathrm{C}}=80 \mathrm{~m} / \mathrm{min}$. With an unused tool, first a steep rise in maximum Barkhausen noise amplitude $\mathrm{M}_{\mathrm{Max}}$ from about $0.2 \mathrm{~V}$ to $0.27 \mathrm{~V}$ occurs. The $\mathrm{M}_{\text {Max }}$ value remains relatively constant at this high level and then decreases as the milling tool dulls. Milling with worn tools again leads to a maximum Barkhausen noise amplitude of $\mathrm{M}_{\mathrm{Max}}=0.2 \mathrm{~V}$. The coercive force $\mathrm{H}_{\mathrm{CM}}$ rises from a level around $\mathrm{H}_{\mathrm{CM}}=24 \mathrm{~A} / \mathrm{m}$ to a level of about $\mathrm{H}_{\mathrm{CM}}=29 \mathrm{~A} / \mathrm{m}$, as tool wear progresses. This behavior was observed reproducibly for all milling tools during the experiments. The observations, the limit for $\mathrm{M}_{\mathrm{Max}}$ and the limit for $\mathrm{H}_{\mathrm{CM}}$ defined in Section 2 and trend lines for the measurements obtained over one tool life are presented in Figure 3.

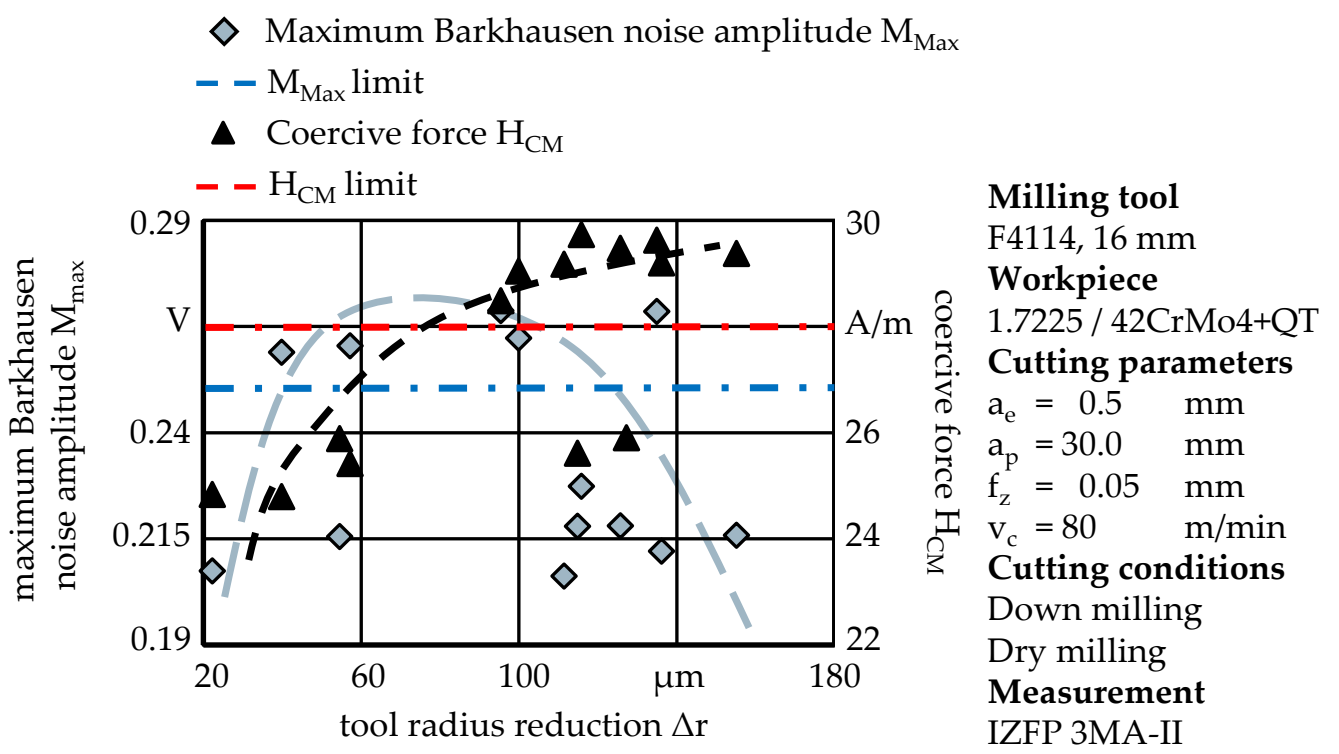

Figure 3. Development of $\mathrm{MM}$ at increasing tool radius reduction $\Delta \mathrm{r}$ for constant cutting parameters.

When cutting with an unused tool, increasing feed per tooth in a range of $f_{z}=0.02$ to $0.04 \mathrm{~mm}$ also increases $\mathrm{M}_{\mathrm{Max}}$, whereas an increase in cutting speed $\mathrm{v}_{\mathrm{C}}$ does not result in significant change of the $\mathrm{M}_{\mathrm{Max}}$. With increasing tool wear, the sensitivity to feed per tooth changes diminishes at $\Delta \mathrm{r}>160 \mu \mathrm{m}$. An increase in feed per tooth $\mathrm{f}_{\mathrm{z}}$ and cutting speed $\mathrm{v}_{\mathrm{C}}$ results in a decrease of $\mathrm{M}_{\mathrm{Max}}$. The coercive force $\mathrm{H}_{\mathrm{CM}}$ shows a strong positive correlation with feed per tooth $\mathrm{f}_{\mathrm{z}}$ and cutting speed $\mathrm{v}_{\mathrm{c}}$ for the entire tool life. The magnitude and sign of the influence of cutting parameter adaptations on MM can therefore assumed to be highly depended on tool wear state. Still, if only $\mathrm{M}_{\mathrm{Max}}$ was considered in the MM measurements, workpiece zones with higher thermal damage cannot be distinguished from surface layers with less thermal damage. Therefore, further measurands of the 3MA-II-sensor need to be taken into account, primarily the coercive force $\mathrm{H}_{\mathrm{CM}}$ [61]. The tendencial increase of coercive force $\mathrm{H}_{\mathrm{CM}}$ for a tool radius reduction of $\Delta \mathrm{r}>90 \mu \mathrm{m}$, as shown in Figure 3, indicates 
a re-hardening zone. When the coercive force limit is exceeded, re-hardening zones in the workpiece are supposed.

\subsection{Adaptive Cutting Processes}

Nevertheless, adapting the cutting parameters to compensate for the influence of tool wear on the MM is feasible. In order to keep the maximum Barkhausen noise amplitude below a limit of $\mathrm{M}_{\mathrm{Max}}<0.25 \mathrm{~V}$ and the coercive force $\mathrm{H}_{\mathrm{CM}}$ below the limit of $28 \mathrm{~A} / \mathrm{m}$, a high feed per tooth of $\mathrm{f}_{\mathrm{z}}=0.06 \mathrm{~mm}$, and a high cutting speed of $\mathrm{v}_{\mathrm{c}}=85 \mathrm{~m} / \mathrm{min}$ can be chosen for the unused tool. Feed per tooth and cutting speed must be reduced with increasing tool radius reduction $\Delta \mathrm{r}$ to about $\mathrm{f}_{\mathrm{z}}=0.01 \mathrm{~mm}$ and $\mathrm{v}_{\mathrm{c}}=45 \mathrm{~m} / \mathrm{min}$. Since further processing supposedly results in re-hardening zones, additional machining was aborted. Measurement data portraying this circumstance and trend lines are visualized in Figure 4.

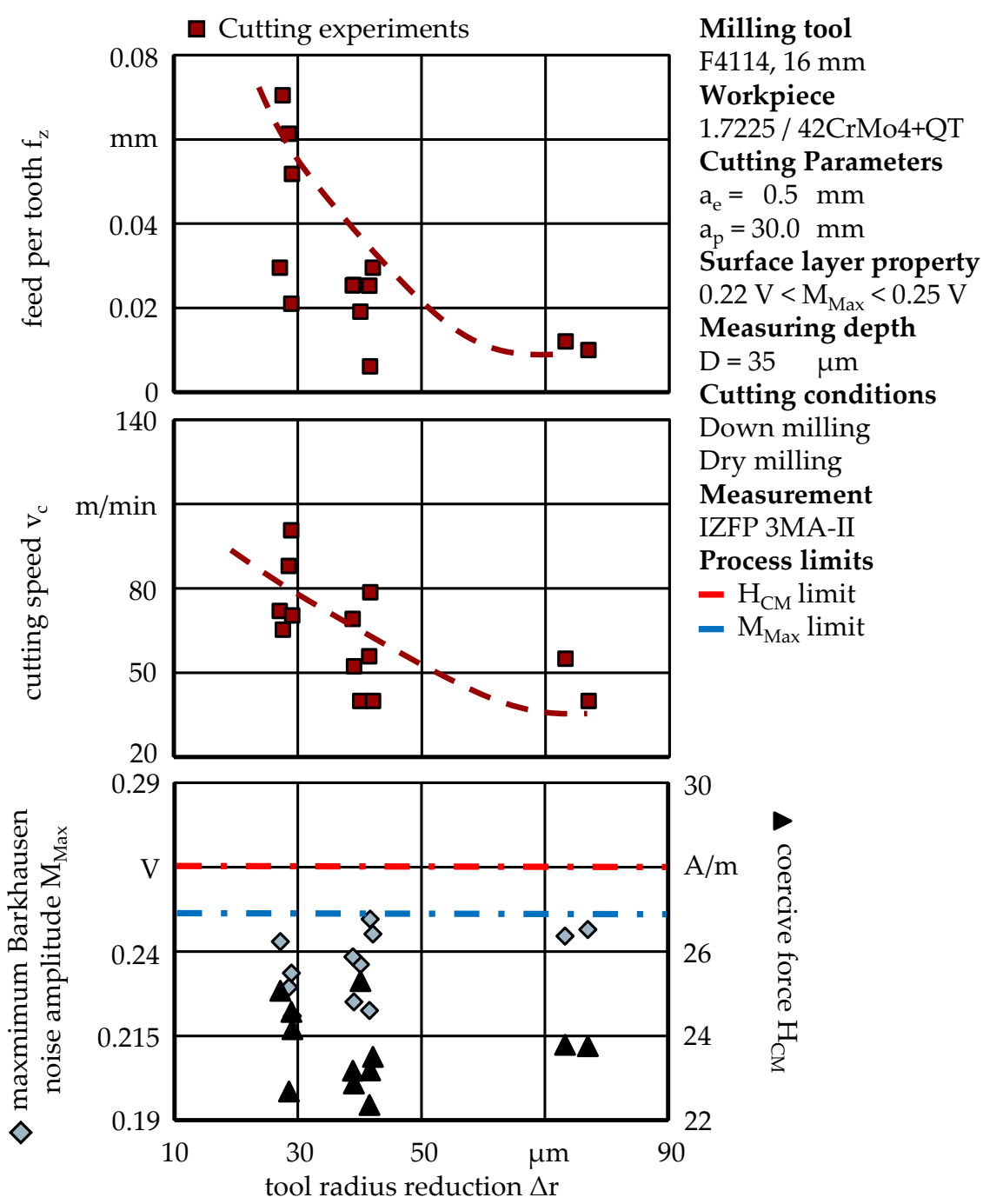

Figure 4. Cutting parameter adaption for compensation of the tool wear influence on MM.

\subsection{Data-Driven Prediction of Micromagnetic Measurements}

In order to investigate the performance of purely data-driven predictions of the MM different machine learning methods have been tested. As model input values feed per tooth $\mathrm{f}_{\mathrm{z}}$, tool radius reduction $\Delta \mathrm{r}$, cutting speed $\mathrm{v}_{\mathrm{C}}$, average power consumption $\mathrm{P}_{\mathrm{M}, \mathrm{Mean}}$, and the standard deviation of power measurement $\mathrm{P}_{\mathrm{M}, \mathrm{Std}}$ were chosen. The model performance has been improved by adding the cube roots of all the mentioned features as inputs. Further input or adding further mathematical functions on the used input did not improve the model performance. Deep NN, random forests, and gradient boosting machine learning 
methods have been tested on the dataset as well. No significant improvement to the performance results presented below could be determined. For the presented methods, the coefficient of determination $\mathrm{R}^{2}$ on the testing set decreases drastically if fewer than $70 \%$ of all samples are used for training. The testing set was fixed at 27 samples for all presented training set magnitudes. It can be observed that purely data-driven approaches to predict MM show a decrease in model performance when the training set is too small, as shown in Figure 5. With sufficient datapoints however, model performance with a coefficient of determination higher than $\mathrm{R}^{2}=0.94$ was achievable.

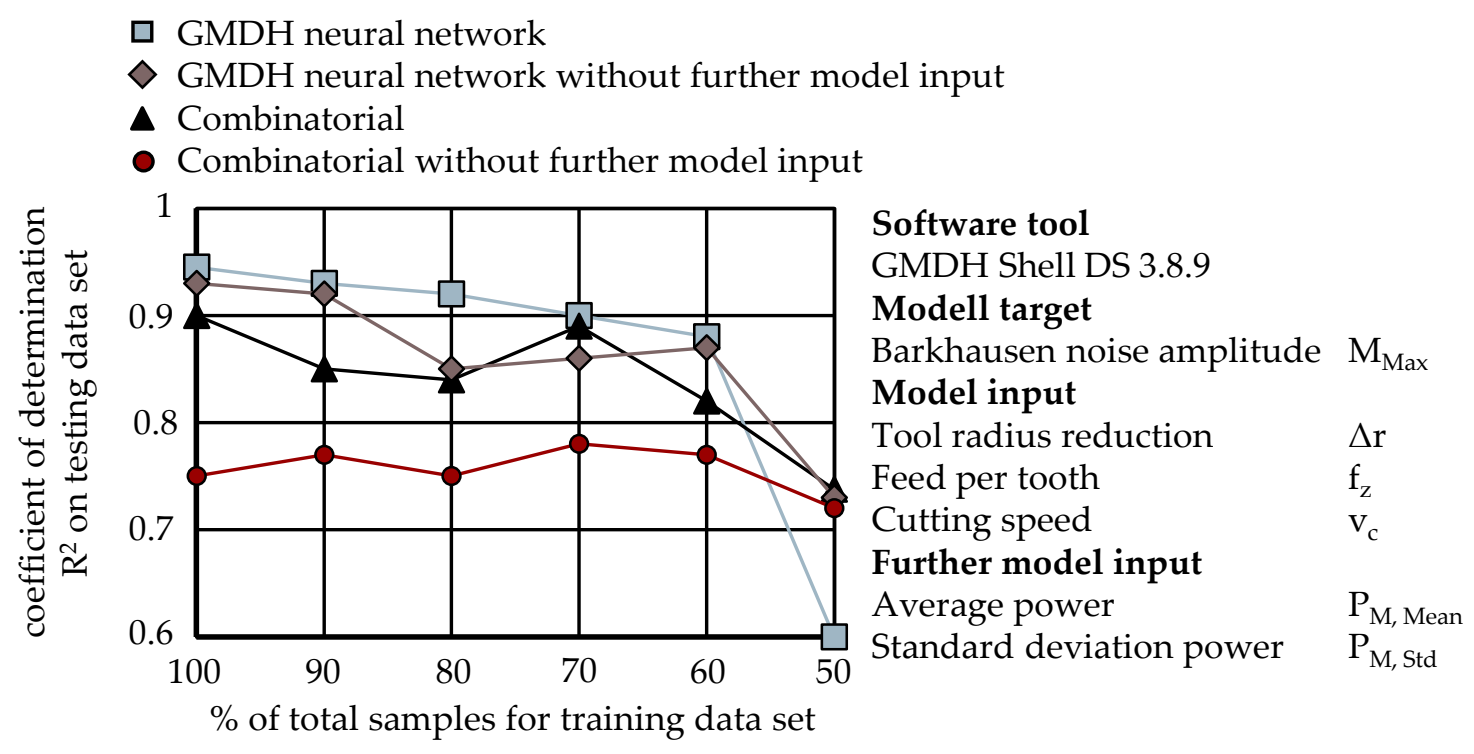

Figure 5. Performance of different machine learning algorithms for different training data set magnitudes.

For the GMDH NN and the combinatorial approach, it is shown that inputting the features aggregated from the power measurement time series leads to a performance increase. The GMDH neural network with the best performance on the testing set of $\mathrm{R}^{2}=0.94$ showed a standard deviation of the residuals on the whole testing set of $\Delta_{\text {MMax }}=0.014 \mathrm{~V}$. Equivalent results were obtained when training GMDH neural networks for other measurands of the 3MA-II-sensor. For example, when choosing coercive force $\mathrm{H}_{\mathrm{CM}}$ as target value with the same inputs as chosen for $\mathrm{M}_{\mathrm{Max}}$, a coefficient of determination on the testing data set of $\mathrm{R}^{2}>0.95$ can be achieved with a standard deviation of the residuals of $\Delta_{\mathrm{HCM}}<0.3 \mathrm{~A} / \mathrm{m}$. For both critical measurands, the standard deviation of the residuals was within the magnitude of the reproducibility of the 3MA-II-sensor measurements investigated in Section 3.1.

\section{Discussion}

The demonstrator setup and the presented approach enables great possibilities for further research and the development of industrially relevant machine learning solutions. It can be concluded that machine learning approaches on modeling MM in combination with a highly automated execution of cutting experiments shows great potential for industrial application. Training data sets for teaching machine learning techniques need to contain a sufficient number of samples. In addition, it was clearly shown that inputting online measurements to the MM prediction model can improve model performance considerably. The approach allows automated and comprehensive parameterization of models for the predictions of MM and, if calibrated, SLP for the specific milling configuration. Therefore, cutting parameters can be adapted in order to keep the MM within defined tolerance bands and avoid re-hardening zones. The introduced level of automation is not limited to the milling process or the prediction of MM. Since the approach is straight-forward, does not rely on complex simulation, and can be exercised for the specific milling process 
configuration at hand, further automation and development of this demonstrator appears worthwhile. The following steps will be taken in further research:

- $\quad 3 M A-I I-s e n s o r$ needs to be calibrated on SLP such as hardness and residual stresses in the workpiece, considering several MM;

- Conducting experiments with more industrially relevant, coated mills;

- Enabling of wet and ultrasonic assisted cutting processes, using the cooling capacity and ultrasonic amplitude as manipulative values;

- Realization of a prediction of a SLP depth gradient;

- Using white or gray box approaches to improve the model performance;

- Investigations on surface layer emergence during the cutting operation with suitable in situ measurement setup.

Author Contributions: Conceptualization, E.U. and T.H.; methodology, T.H.; software, P.S. and Y.B.; validation, T.H., P.S. and Y.B.; formal analysis, T.H.; investigation, T.H.; resources, E.U.; data curation, P.S. and Y.B.; writing—original draft preparation, T.H.; writing—review and editing, E.U., P.S. and Y.B.; visualization, T.H.; supervision, E.U.; project administration, E.U. All authors have read and agreed to the published version of the manuscript.

Funding: This research received no external funding.

Data Availability Statement: All developed software and obtained measurement data can be downloaded on https://git.tu-berlin.de/tholznagel/surfacelayerpropertyprediction (accessed on 27 September 2021).

Acknowledgments: We acknowledge support by the German Research Foundation and the Open Access Publication Fund of TU Berlin.

Conflicts of Interest: The authors declare no conflict of interest.

\section{References}

1. $\quad$ Denkena, B.; Tönshoff, H.K. Spanen, 3rd ed.; Springer: Heidelberg, Germany, 2011; pp. 87-212.

2. Saldana, C.; Swaminathan, S.; Brown, T.L.; Moscoso, W.; Mann, J.B.; Compton, W.D.; Chandrasekar, S. Unusual Applications of Machining: Controlled Nanostructuring of Materials and Surfaces. J. Manuf. Sci. Eng. 2010, 132, 030908. [CrossRef]

3. M'Saoubi, R.; Outeiro, J.C.; Chandrasekaran, H.O.W.D.; Dillon, O.W., Jr.; Jawahir, I.S. A review of surface integrity in machining and its impact on functional performance and life of machined products. Int. J. Sustain. Manuf. 2008, 1, 203. [CrossRef]

4. Neubauer, T.; Poll, G.; Denkena, B.; Maiß, O. Untersuchungen einer Lebensdauererhöhung von Zylinderrollenlagern durch eine gezielte Modifikation der Randzone. VDI-B 2013, 2202, 1-14.

5. Sales, W.F.; Schoop, J.; da Silva, L.R.R.; Machado, Á.R.; Jawahir, I.S. A review of surface integrity in machining of hardened steels. J. Man. Proc. 2020, 58, 136-216. [CrossRef]

6. Wittel, H.; Jannasch, D.; Muhs, D. Roloff/Matek Maschinenelemente, 19th ed.; Vieweg+Teubner Verlag: Wiesbaden, Germany, 2009; pp. 114-182.

7. Chi, J.; Cai, Z.; Wan, Z.; Zhang, H.; Chen, Z.; Li, L.; Li, Y.; Peng, P.; Guo, W. Effects of heat treatment combined with laser shock peening on wire and arc additive manufactured Ti17 titanium alloy: Microstructures, residual stress and mechanical properties. Surf. Coat. Technol. 2020, 396, 125908. [CrossRef]

8. Terres, M.; Ben Mohamed, S.; Sidhom, H. Influence of ion nitriding on fatigue strength of low-alloy (42CrMo4) steel: Experimental characterization and predictive approach. Int. J. Fatigue 2010, 32, 1795-1804. [CrossRef]

9. Röttger, K.; Wilcke, G.; Mader, S. Festwalzen-eine Technologie für effizienten Leichtbau. Mater. Werkst. 2005, 36, $270-274$. [CrossRef]

10. Lienert, F.; Hoffmeister, J.; Schulze, V. Residual Stress Depth Distribution after Piezo Peening of Quenched and Tempered AISI 4140. Mater. Sci. Forum 2013, 768-769, 526-533. [CrossRef]

11. Lin, Q.; Liu, H.; Zhu, C.; Chen, D.; Zhou, S. Effects of different shot peening parameters on residual stress, surface roughness and cell size. Surf. Coat. Technol. 2020, 398, 126054. [CrossRef]

12. Crouch, A.E.; Beuker, T. In-Line Stress Measurement by the Continuous Barkhausen Method. In Proceedings of the IPC, Alberta, AB, Canada, 4-8 September 2004. [CrossRef]

13. Willcox, M.; Mysak, T. An Introduction to Barkhausen Noise and its Applications. Insight NDT 2004, 12, 1-19.

14. Le Manh, T.; Pérez Benitez, J.A.; Alberteris, M. Future trend and applications of Barkhausen noise. In Barkhausen Noise for Non-Destructive Testing and Materials Characterization in Low Carbon Steels, 2nd ed.; Le Manh, T., Benitez, P., Alberto, J., Alberteris, M., Eds.; Woodhead Publishing: Duxford, UK, 2020. [CrossRef]

15. Seidel, M.W. Schleifbrand und dessen Prüfung. Leitfaden für die Praxis, 1st ed.; Hanser: Munich, Germany, 2020; pp. 25-78. 
16. Heisel, U.; Klocke, F.; Uhlmann, E.; Spur, G. Spanen, 1st ed.; Hanser: Munich, Germany, 2014; p. 535.

17. Klocke, F. Fertigungsverfahren 1, 9th ed.; Springer+Vieweg: Berlin, Germany, 2018; pp. 325-425.

18. El-Khabeery, M.; Fattouh, M. Residual stress distribution caused by milling. Int. J. Mach. Tools Manuf. 1989, 29, 391-401. [CrossRef]

19. Köhler, J.; Grove, T.L.; Mais, O.; Denkena, B. Residual Stresses in Milled Titanium Parts. Procedia CIRP 2012, 2, 79-82. [CrossRef]

20. Perez, I.; Madariaga, A.; Cuesta, M.; Garay, A.; Arrazola, P.; Ruiz, J.; Rubio, F.; Sanchez, R. Effect of cutting speed on the surface integrity of face milled 7050-T7451 aluminium workpieces. Procedia CIRP 2018, 71, 460-465. [CrossRef]

21. Javidikia, M.; Sadeghifar, M.; Songmene, V.; Jahazi, M. Effect of turning environments and parameters on surface integrity of AA6061-T6: Experimental analysis, predictive modeling, and multi-criteria optimization. Int. J. Adv. Manuf. Technol. 2020, 110, 2669-2683. [CrossRef]

22. Wimmer, M.; Hameed, M.Z.S.; Wölfle, C.; Weisbrodt, V.; Zaeh, M.F.; Werner, E.; Krempaszky, C.; Semm, T. The influence of the process parameters on the surface integrity during peripheral milling of Ti-6Al-4V. TM-Tech. Mess. 2020, 87, 721-731. [CrossRef]

23. Deselaers, L. Spannungen in der Berührungs und Scherzone sowie Aufhärtung der Randzone beim Umfangsfräsen mit Hartmetall. Arch. Eise. 1971, 42, 495-499.

24. Holmberg, J.; Wretland, A.; Berglund, J.; Beno, T.; Karlsson, A.M. Surface Integrity Investigation to Determine Rough Milling Effects for Assessment of Machining Allowance for Subsequent Finish Milling of Alloy 718. J. Manuf. Mater. Process. 2021, 5, 48. [CrossRef]

25. Oliveira, G.D.P.; Fonseca, M.C.; Araujo, A.C. Residual stresses and cutting forces in cryogenic milling of Inconel 718. Procedia CIRP 2018, 77, 211-214. [CrossRef]

26. Ankener, W.; Uebel, J.; Basten, S.; Smaga, M.; Kirsch, B.; Seewig, J.; Aurich, J.C.; Beck, T. Influence of different cooling strategies during hard turning of AISI 52100 - part II: Characterization of the surface and near surface microstructure morphology. Procedia CIRP 2020, 87, 119-124. [CrossRef]

27. Chavan, A.; Sargade, V. Surface Integrity of AISI 52100 Steel during Hard Turning in Different Near-Dry Environments. Adv. Mater. Sci. Eng. 2020, 4256308, 1-13. [CrossRef]

28. Tong, J.; Zhao, J.; Chen, P.; Zhang, Z.; Zhao, B. Effect of ultrasonic longitudinal-torsional composite milling of the residual stress on the surface of titanium alloy. Proc. Inst. Mech. Eng. Part C J. Mech. Eng. Sci. 2019, 234, 1598-1608. [CrossRef]

29. Ying, N.; Feng, J.; Bo, Z.; Guofu, G.; Jing-Jing, N. Theoretical investigation of machining-induced residual stresses in longitudinal torsional ultrasonic-assisted milling. Int. J. Adv. Manuf. Technol. 2020, 108, 3689-3705. [CrossRef]

30. Tang, Z.; Liu, Z.; Pan, Y.; Wan, Y.; Ai, X. The influence of tool flank wear on residual stresses induced by milling aluminum alloy. J. Mater. Process. Technol. 2009, 209, 4502-4508. [CrossRef]

31. Holmberg, J.; Wretland, A.; Berglund, J.; Beno, T. A detailed investigation of residual stresses after milling Inconel 718 using typical production parameters for assessment of affected depth. Mater. Today Commun. 2020, 24, 100958. [CrossRef]

32. Liang, X.; Liu, Z.; Chen, L.; Hao, G.; Wang, B.; Cai, Y.; Song, Q. Tool wear induced modifications of plastic flow and deformed material depth in new generated surfaces during turning Ti-6Al-4V. J. Mater. Res. Technol. 2020, 9, 10782-10795. [CrossRef]

33. Oliveira, A.R.F.; da Silva, L.R.R.; Baldin, V.; Fonseca, M.P.C.; Silva, R.B.; Machado, A.R. Effect of tool wear on the surface integrity of Inconel 718 in face milling with cemented carbide tools. Wear 2020, 86, 203752-203759. [CrossRef]

34. González, G.; Plogmeyer, M.; Zanger, F.; Biehl, S.; Bräuer, G.; Schulze, V. Effect of tool coatings on surface grain refinement in orthogonal cutting of AISI 4140 steel. Procedia CIRP 2020, 87, 176-180. [CrossRef]

35. Junge, T.; Liborius, H.; Mehner, T.; Nestler, A.; Schubert, A.; Lampke, T. Method for process monitoring of surface layer changes in turning of aluminium alloys using tools with a flank face chamfer. Procedia CIRP 2020, 87, 432-437. [CrossRef]

36. Denkena, B.; Breidenstein, B.; Dittrich, M.-A.; Nguyen, H.N.; Fricke, L.V.; Maier, H.J.; Zaremba, D. Effects on the deformationinduced martensitic transformation in AISI 304 in external longitudinal turning. Adv. Ind. Manuf. Eng. 2021, 2, 100044. [CrossRef]

37. Kundrák, J.; Mamalis, A.G.; Szabó, G.; Pálmai, Z.; Gyáni, K. Numerical examination of residual stresses developing during hard turning at different rake angles. Int. J. Adv. Manuf. Technol. 2016, 89, 1989-1999. [CrossRef]

38. Roeder, M. Spanbildung und Werkzeugverschleiß bei der Zerspanung partikelverstärkter Titanmatrix-Verbundwerkstoffe. Master's Thesis, Technical University Berlin, Berlin, Germany, 2013.

39. Lebsanft, M.; Tiffe, M.; Zabel, A.; Zinn, W.; Biermann, D.; Scholtes, B. Residual Stresses in Different Heat Treated Workpieces after Turning. Adv. Mater. Res. 2014, 996, 652-657. [CrossRef]

40. Uebel, J.; Ströer, F.; Basten, S.; Ankener, W.; Hotz, H.; Heberger, L.; Stelzer, G.; Kirsch, B.; Smaga, M.; Seewig, J.; et al. Approach for the observation of surface conditions in-process by soft sensors during cryogenic hard turning. Procedia CIRP 2019, 81, 1260-1265. [CrossRef]

41. Zahoor, S.; Mufti, N.A.; Saleem, M.Q.; Shehzad, A. An investigation into surface integrity of AISI P20 machined under the influence of spindle forced vibrations. Int. J. Adv. Manuf. Technol. 2018, 96, 3565-3574. [CrossRef]

42. Zagórski, I.; Korpysa, J.; Weremczuk, A. Influence of Tool Holder Types on Vibration in Rough Milling of AZ91D Magnesium Alloy. Materials 2021, 14, 2517. [CrossRef] [PubMed]

43. Ulutan, D.; Ozel, T. Machining induced surface integrity in titanium and nickel alloys: A review. Int. J. Mach. Tools Manuf. 2011, 51, 250-280. [CrossRef]

44. El-Axir, M. A method of modeling residual stress distribution in turning for different materials. Int. J. Mach. Tools Manuf. 2002, 42, 1055-1063. [CrossRef] 
45. Wang, S.Y.; Ai, X.; Zhao, J.; Lv, Z. FEM Simulation of the Residual Stress in the Machined Surface Layer for High-Speed Machining. Key Eng. Mater. 2006, 315-316, 140-144. [CrossRef]

46. Zhang, J.; Liang, S.; Zhang, G.; Yen, D. Modeling of Residual Stress Profile in Finish Hard Turning. Mater. Manuf. Process. 2006, 21, 39-45. [CrossRef]

47. Umbrello, D.; Ambrogio, G.; Filice, L.; Shivpuri, R. An ANN approach for predicting subsurface residual stresses and the desired cutting conditions during hard turning. J. Mater. Process. Technol. 2007, 189, 143-152. [CrossRef]

48. Umbrello, D.; Ambrogio, G.; Filice, L.; Shivpuri, R. A hybrid finite element method-artificial neural network approach for predicting residual stresses and the optimal cutting conditions during hard turning of AISI 52100 bearing steel. Mater. Des. 2008, 29, 873-883. [CrossRef]

49. Saini, S.; Ahuja, I.S.; Sharma, V.S. Modelling the effects of cutting parameters on residual stresses in hard turning of AISI H11 tool steel. Int. J. Adv. Manuf. Technol. 2012, 65, 667-678. [CrossRef]

50. Ulutan, D.; Arisoy, Y.M.; Özel, T.; Mears, L. Empirical Modeling of Residual Stress Profile in Machining Nickel-based Superalloys Using the Sinusoidal Decay Function. Procedia CIRP 2014, 13, 365-370. [CrossRef]

51. Wang, J.; Zhang, D.; Wu, B.; Luo, M. Numerical and Empirical Modelling of Machining-induced Residual Stresses in Ball end Milling of Inconel 718. Procedia CIRP 2017, 58, 7-12. [CrossRef]

52. Schulze, V.; Uhlmann, E.; Mahnken, R.; Menzel, A.; Biermann, D.; Zabel, A.; Bollig, P.; Ivanov, I.M.; Cheng, C.; Holtermann, R.; et al. Evaluation of different approaches for modeling phase transformations in machining simulation. Prod. Eng. 2015, 9, 437-449. [CrossRef]

53. Huang, X.; Zhang, X.; Ding, H. An Enhanced Analytical Model of Residual Stress for Peripheral Milling. Procedia CIRP 2017, 58, 387-392. [CrossRef]

54. Yang, D.; Xiao, X.; Liang, X. Analytical modeling of residual stress in orthogonal cutting considering tool edge radius effect. Int. J. Adv. Manuf. Technol. 2019, 103, 2965-2976. [CrossRef]

55. Uhlmann, E.; Mahnken, R.; Ivanov, I.; Cheng, C. FEM modeling of hard turning with consideration of viscoplastic asymmetry and phase transformation. J. Mach. Eng. 2013, 13, 80-92.

56. Stampfer, B.; Böttger, D.; Gauder, D.; Zanger, F.; Häfner, B.; Straß, B.; Wolter, B.; Lanza, G.; Schulze, V. Experimental identification of a surface integrity model for turning of AISI4140. Procedia CIRP 2020, 87, 83-88. [CrossRef]

57. Meurer, M.; Tekkaya, B.; Augspurger, T.; Pullen, T.; Schraknepper, D.; Bergs, T.; Münstermann, S. Cutting force based surface integrity soft-sensor when hard machining AISI 4140. Tm Tech. Mess. 2020, 87, 683-693. [CrossRef]

58. Fricke, L.V.; Barton, S.; Nguyen, H.N.; Breidenstein, B.; Zaremba, D. Integration von Wirbelstromsensoren in eine Drehmaschine als Grundlage für eine prozessbegleitende Regelung-Eine Übersicht über resultierende Störeinflüsse. DACH Jahr 2019, 1, 1-9.

59. Fricke, L.V.; Nguyen, H.N.; Breidenstein, B.; Zaremba, D.; Maier, H.J. Eddy Current Detection of the Martensitic Transformation in AISI304 Induced upon Cryogenic Cutting. Steel Res. Int. 2020, 92. [CrossRef]

60. Fricke, L.V.; Nguyen, H.N.; Breidenstein, B.; Denkena, B.; Dittrich, M.-A.; Maier, H.J.; Zaremba, D. Generation of tailored subsurface zones in steels containing metastable austenite by adaptive machining and validation by eddy current testing. Tm Tech. Mess. 2020, 87, 704-713. [CrossRef]

61. Altpeter, I.; Boller, C.; Kopp, M.; Wolter, B.; Fernath, R.; Hirninger, B.; Werner, S. Zerstörungsfreie Detektion von Schleifbrand mittels elektromagnetischer Prüftechniken. Proc. DGZfP-Jahrestag. 2011, 30, 1-10. 